\title{
Does Shamblin classification affect the clinical outcomes following carotid body tumor excision?
}

\author{
Hasan Erdem (1D) \\ Department of Cardiovascular Surgery, Koşuyolu High Specialty Education and Research Hospital, Istanbul, Turkey
}

Received: April 26, 2021 Accepted: June 02, 2021 Published online: August 11, 2021

\begin{abstract}
Objectives: In this study, we present the late results of patients who underwent carotid body tumor (CBT) resection and compared postoperative complication rates according to the Shamblin classification.

Patients and methods: Between April 2012 and April 2019, a total of 55 consecutive patients (20 males, 35 females; mean age: $56.2 \pm 1.8$ years; range, 38 to 62 years) who were operated for CBTs were retrospectively analyzed. The patients were classified according to the Shamblin classification. Demographic and clinical characteristics of the patients, postoperative complications, total amount of drainage, and length of hospital and intensive care unit stay were recorded.

Results: Carotid body tumors were bilateral in five patients, while they involved only the right side in 23 and left side in 27 patients. The CBTs were Shamblin type 1 in 16, type 2 in 31, and type 3 in eight patients. Intraoperative vascular reconstruction was required in eight patients. Early postoperative morbidities were transient ischemic attack (TIA) in three, cranial involvement in nine, middle cerebral artery occlusion in one, dysphonia in six, dysphagia in six, and hemiparesthesia in one patient. Permanent neurological damage (hoarseness $10.9 \%$, ptosis $45 \%$, internal carotid artery $1.81 \%$ ) was seen in $18.2 \%$ of the cases. The length of stay in the hospital and intensive care unit, total amount of drainage, rates of postoperative cranial nerve involvement, permanent neurological damage, disease recurrence, postoperative TIA, and dysphagia were found to be significantly increased in patients in the Shamblin type 3 ( $p<0.005$ ).

Conclusion: Surgery can be performed safely in Shamblin type 1 and 2 tumors, while surgery requires a more meticulous manipulation for type 3 tumors, as these tumors are associated with high cranial nerve damage and complication rates.
\end{abstract}

Keywords: Carotid body tumors, neurological deficit, Shamblin classification.

Carotid body tumors (CBTs) are rarely vascular neoplasms arising from paraganglionic cells (precursors of neural cleft tissues) of the carotid bifurcation. The incidence of CBT is about $1 / 30,000{ }^{[1]}$ These tumors are bilateral in $10 \%$ and familial in $10 \%$ of the cases. ${ }^{[2]}$ Compared to all head and neck tumors, its overall incidence is less than $0.5 \%$ and its annual incidence is $0.001 \%{ }^{[3]}$ Clinically, CBTs are palpable on physical examination as insensitive rubbery pulsatile masses. ${ }^{[4]}$ These masses can be displaced both horizontally and vertically due to their adhesion to the carotid artery. ${ }^{[5]}$ Although these tumors are histopathologically benign, they can be considered clinically malignant due to their involvement in neurovascular structures and intracranial invasion. The disease is thought to develop secondary to chronic hypoxia at higher altitudes. ${ }^{[2]}$

Surgical excision of CBTs is the gold standard for curative treatment of CBTs. ${ }^{[6]}$ In 1971, Shamblin et al. ${ }^{[7]}$ divided them into three categories according to the tumoral invasion of the carotid artery (Table 1).
Surgical removal of CBTs is challenging due to their close proximity to the vital structures (Figure 1). ${ }^{[8]}$

Asymptomatic patients usually present to the outpatient clinic with complaints of swelling on the neck. The diagnosis is often confirmed by Duplex ultrasound, computed tomography (CT), magnetic resonance imaging (MRI) and, rarely, conventional angiography. ${ }^{[9]}$

In this study, we present the surgical results of CBT resection and long-term outcomes of patients who underwent glomus tumor resection in our clinic.

Corresponding author: Hasan Erdem, MD. Kartal Koşuyolu Yüksek İhtisas Eğitim ve Araştırma Hastanesi Kalp ve Damar Cerrahisi Kliniği, 34865 Kartal, İstanbul, Turkey.

Tel: +90 532 - 3937787 e-mail: herdemkvc@hotmail.com

\section{Citation:}

Erdem H. Does Shamblin classification affect the clinical outcomes following carotid body tumor excision? Cardiovasc Surg Int 2021;8(2):91-97. 


\begin{tabular}{ll} 
& \multicolumn{1}{c}{ Table 1} \\
& \multicolumn{1}{c}{ Shamblin staging in carotid body tumors } \\
\hline Type 1 & Tumor minimally invades the carotid artery. It is easy to excise \\
Type 2 & Tumor partially invades the carotid artery. It is adhered to adventitia. \\
Type 3 & Tumor completely surrounded the carotid arteries. Carotid revascularization is required.
\end{tabular}

Additionally, the necessity and complication rates of vascular reconstruction without embolization and devascularization of the external carotid artery (ECA) in surgically resected CBTs were discussed.

\section{PATIENTS AND METHODS}

This single-center, retrospective study was conducted at University of Health Sciences, Koşuyolu High Specialty Education and Research Hospital, Cardiovascular Surgery between April 2012 and April 2019. A total of 55 consecutive patients (20 males, 35 females; mean age: $56.2 \pm 1.8$ years; range, 38 to 62 years) who were operated for CBTs were included. Duplex ultrasonography, CT, and MRI were used for diagnostic purposes. Tumors were classified according to the Shamblin classification. Diagnostic angiography was performed for tumors larger than $4 \mathrm{~cm}$. The purpose of performing angiography in these patients was to identify intracerebral circulation and determine the possible indication of carotid artery clamping. Preoperative embolization was not performed in any patient.

Demographic data, clinical presentations, bilaterality, family history, and tumor size were recorded. Postoperative complications (neurological events, cranial nerve injury), total amount of drainage, stay in intensive care unit, and hospital stay were evaluated. Early mortality was defined as hospital mortality within 30 days. Follow-up data were obtained from the outpatient records of the hospital registry. The patients who were followed outside the reference hospital were contacted by telephone and the assessment was performed based on their medical records.
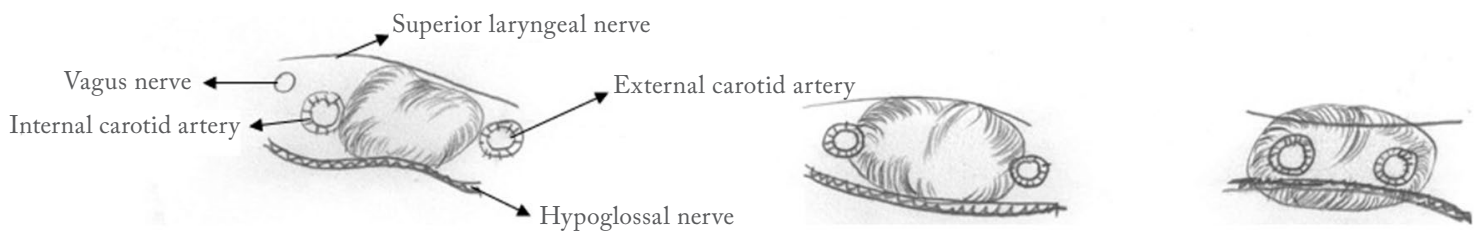

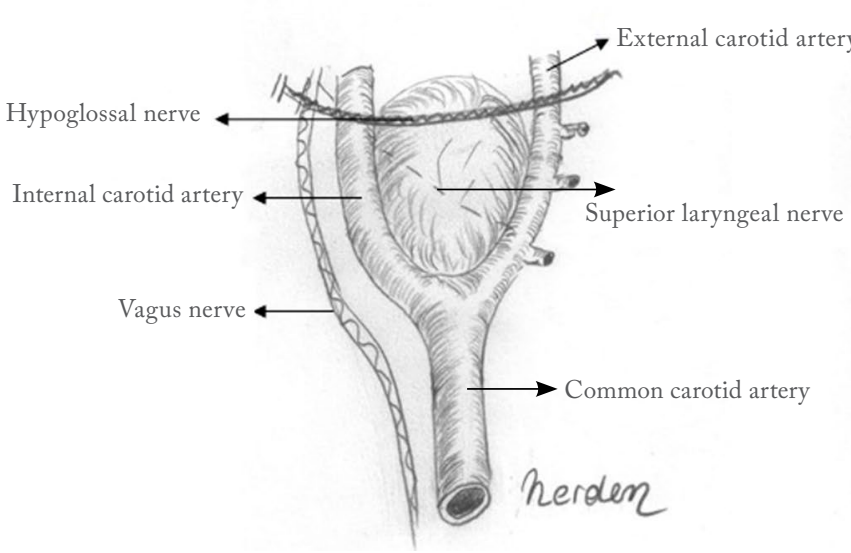

Type I

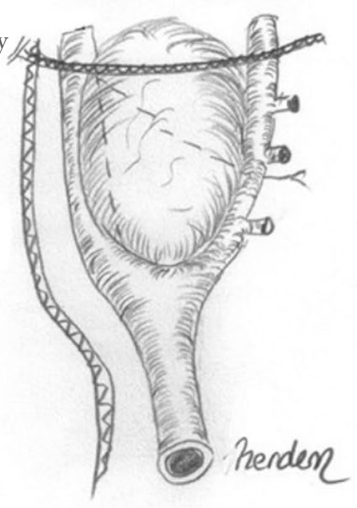

Type II

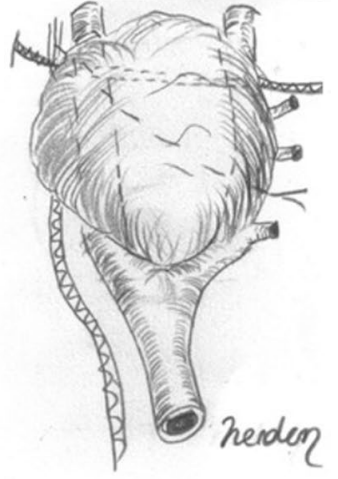

Type III

Figure 1. Shamblin classification. 

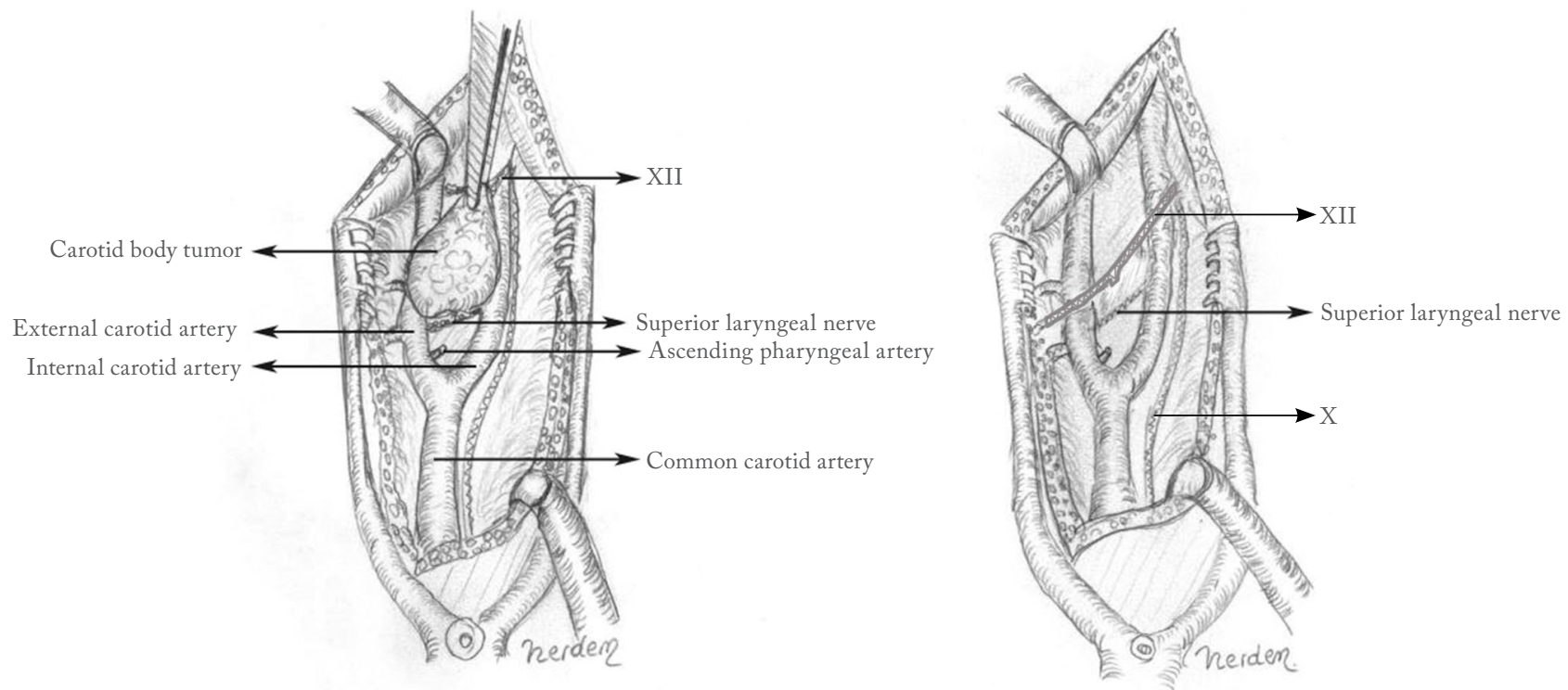

Figure 2. Illustration for carotid body tumor resection.

\section{Surgical technique}

Under general anesthesia, all patients were placed in supine position on the operating table with their necks in hyperextension. After the head was brought to extension, it was turned away from the side to be operated. The area with the lesion was positioned on the upper side. The surgical intervention was initiated with a vertical 5 to $8-\mathrm{cm}$ incision extended vertically along the anterior edge of the sternocleidomastoid muscle toward the earlobe and sternal (notch) jugulum.

\begin{tabular}{|c|c|c|c|}
\hline \multicolumn{4}{|c|}{$\begin{array}{c}\text { Table } 2 \\
\text { Baseline characteristics of study population }\end{array}$} \\
\hline & $\mathrm{n}$ & $\%$ & Mean \pm SD \\
\hline Age (year) & & & $56.2 \pm 1.79$ \\
\hline \multicolumn{4}{|l|}{ Sex } \\
\hline Male & 20 & 35.7 & \\
\hline Female & 35 & 62.5 & \\
\hline \multicolumn{4}{|l|}{ Symptoms } \\
\hline Swelling in the neck & 37 & 67.3 & \\
\hline Dizziness & 11 & 20 & \\
\hline Others & 7 & 12.7 & \\
\hline \multicolumn{4}{|l|}{ Laterality } \\
\hline Right & 23 & 41.1 & \\
\hline Left & 27 & 48.2 & \\
\hline Bilateral & 5 & 9.1 & \\
\hline \multicolumn{4}{|l|}{ Shamblin types } \\
\hline 1 & 16 & 28.6 & \\
\hline 2 & 31 & 55.4 & \\
\hline 3 & 8 & 14.3 & \\
\hline \multicolumn{4}{|c|}{ Tumor size (on longitudinal axis) } \\
\hline$<4 \mathrm{~cm}$ & 30 & 3.6 & \\
\hline$>4 \mathrm{~cm}$ & 25 & 44.6 & \\
\hline SD: Standard deviation. & & & \\
\hline
\end{tabular}




\begin{tabular}{|lcc|}
\multicolumn{4}{c}{ Table 3 } & & \\
\hline Complications & $\mathrm{n}$ & $\%$ \\
\hline TIA & 3 & 5.4 \\
Cranial nerve involvement & 8 & 14.5 \\
5 & 1 & 1.8 \\
7 & 4 & 7.2 \\
9 & 1 & 1.8 \\
10 & 1 & 1.8 \\
12 & 1 & 1.8 \\
MCA occlusion & 1 & 1.8 \\
Dysphonia & 6 & 10.9 \\
Dysphagia & 6 & 10.9 \\
Horner syndrome & 2 & 3.6 \\
Permanent neurological damage & 10 & 18.2 \\
Inadequate resection & 7 & 12.7 \\
\hline TIA: Transient ischemic attack; MCA: Middle cerebral artery. & \\
\hline
\end{tabular}

Common carotid artery, internal carotid artery (ICA), ECA, and superior thyroid artery were wrapped, retracted with a tape, and kept under control.

During the operation, arterial blood flow was not interrupted by clamping, any shunt was not used and, therefore, heparinization was not performed. Before resection of the tumor, vagus and hypoglossal nerves were identified. Bipolar cautery was used to reduce bleeding and minimize nerve damage. The necessary areas were dissected bluntly with cautery. The cleavage between the carotid artery and the tumor was identified under adventitia, and the dissection was initiated from the appropriate place. Thanks to the appropriate surgical maneuvers performed, the tumors were often resected almost completely (Figure 2).

Since Shamblin type 3 tumors with a greater diameter progressed toward the skull base and surrounded vascular structures more closely, surgery was terminated in a certain area. Blood pressure was followed with arterial monitoring, and cerebral oxygenation was monitored with cerebral near-infrared spectroscopy. For monitoring, arterial blood pressure were attempted to be kept at normotensive levels.

All patients were scheduled for follow-up using Doppler ultrasound at one and six months and annually thereafter. In patients with a positive family history or tumor recurrence history, annual controls were performed with MRI.

\section{Statistical analysis}

Statistical analysis was performed using the IBM SPSS version 23.0 software (IBM Corp., Armonk, NY, USA). Descriptive data were expressed in mean \pm standard deviation (SD), median (min-max) or number and frequency. The Kolmogorov-Smirnov normality test was used to examine the distribution of variables. One-way analysis of variance (ANOVA) was used to compare variables showing normal distribution among multiple groups, while the Tukey test and Bonferroni correction analyses were used in the comparison of subgroups. In a comparison of more

\begin{tabular}{|c|c|c|c|c|c|c|c|}
\hline \multirow[b]{3}{*}{ Postoperative complications } & \multicolumn{6}{|c|}{$\begin{array}{l}\text { Table } 4 \\
\text { nes according to Shamblin classification }\end{array}$} & \multirow[b]{3}{*}{$p$} \\
\hline & \multicolumn{2}{|c|}{ Shamblin 1} & \multicolumn{2}{|c|}{ Shamblin 2} & \multicolumn{2}{|c|}{ Shamblin 3} & \\
\hline & $\mathrm{n}$ & Mean \pm SD & $\mathrm{n}$ & Mean \pm SD & $\mathrm{n}$ & Mean \pm SD & \\
\hline ICU stay & & $1.9 \pm 0.1$ & & $1.9 \pm 0.1$ & & $5.4 \pm 2.4$ & 0.003 \\
\hline Hospital stay & & $7.9 \pm 0.6$ & & $9.3 \pm 0.7$ & & $17.9 \pm 6.6$ & 0.248 \\
\hline Drainage $(\mathrm{mL})$ & & $48.4 \pm 6.3$ & & $68.8 \pm 12.8$ & & $118.8 \pm 26.6$ & 0.004 \\
\hline Permanent neurological damage & 1 & & 2 & & 7 & & 0 \\
\hline TIA & 0 & & 0 & & 3 & & 0.01 \\
\hline Dysphagia & 0 & & 2 & & 4 & & 0.003 \\
\hline Dysphonia & 0 & & 3 & & 3 & & 0.055 \\
\hline Cranial nerve involvement & 1 & & 2 & & 6 & & 0.013 \\
\hline Recurrence & 0 & & 2 & & 5 & & 0.013 \\
\hline
\end{tabular}


than two independent samples that were not normally distributed, the Kruskal-Wallis test was employed. A $p$ value of $<0.05$ was considered statistically significant.

\section{RESULTS}

The patients presented to the outpatient clinic for isolated swelling on the neck $(n=37,67.3 \%)$, dizziness $(\mathrm{n}=11,20 \%)$, and other indications $(\mathrm{n}=7,12.7 \%)$. Preoperative neurological findings were normal in all patients. All patients were evaluated by CT preoperatively. The MRI was performed in 33 patients and preoperative angiography in six patients. Baseline characteristics of the patients are presented in Table 2. The largest and the smallest CBTs were $7.7 \times 5.5 \times 5.4 \mathrm{~cm}$ in diameter and $1.13 \times 0.77 \times 1.3 \mathrm{~cm}$ in diameter, respectively. In four patients with Shamblin type 3 CBTs, ICA was repaired with grafts $(n=4,7.2 \%)$. A saphenous patch was used in one (1.81\%) patient, and the polytetrafluoroethylene (PTFE) patch in three (5.4\%) patients. The ECA was ligated in three (5.4\%) patients.

The median follow-up was five (range, 2 to 9) years. There was no disease-specific mortality during the follow-up period. One $(n=1,1.81 \%)$. patient died of coronary artery disease five months after surgery. Disease recurrence $(n=4)$ or insufficient resection $(\mathrm{n}=3)$ was seen in seven $(\mathrm{n}=7,12.72 \%)$ Patients. These patients received postoperative radiotherapy. Postoperative neurological complications were shown in Table 3.

The length of stay in the intensive care unit, duration of hospital, total amount of drainage, rates of postoperative cranial nerve involvement, permanent neurological damage, disease recurrence, postoperative transient ischemic attack, and dysphagia were found to be increased significantly in patients in the Shamblin type 3 subgroup, compared to the other groups $(\mathrm{p}<0.05)$. Table 4 shows the comparison of postoperative results according to by Shamblin type.

\section{DISCUSSION}

Total resection is recommended due to the rare malignant potential of CBTs. Resection can be technically difficult in patients with a larger tumor size and, particularly, in cases with Shamblin type 3. Detection of the tumor when it is of small size results in favorable surgical outcomes, whereas a scarce number of clinical symptoms in the early period may lead to the establishment of the diagnosis of these tumors in the long-term when they reach larger sizes. In this study, almost half of the patients had tumors larger than $4 \mathrm{~cm}$. Surgical risk is higher in patients with Shamblin type 3 CBTs and, particularly, in cases with large tumoral masses. We believe that the major challenge in CBT management is the late referral of patients to surgery due to the difficulties in diagnosis.

Histopathological analysis of the tumor reveals a weak malignant potential in 5\% of glomus tumors. Therefore, malignancy is defined only by the presence of distant metastases. ${ }^{[10]}$ In this study, any evidence of malignancy was not found in the follow-up period of patients. There is a familial predisposition in 7 to $9 \%$ of the cases. ${ }^{[2]}$ In this study, family history was obtained in only four (7.27\%) patients. In this series, 35 women $(63.6 \%)$ and 20 men (36.6\%) were included. Bilateral CBTs were seen in $10 \%$ of the cases. In this report, these rates are consistent with the literature (9.1\%) (Figure 3). ${ }^{[2]}$

The risk of cranial nerve paralysis has been reported at a rate of 10 to $40 \%$ in surgical resection of CBTs. ${ }^{[11,12]}$ Therefore, the risk of serious complications after surgical treatment appears to be an important factor in decision-making for each individual patient. In our study, this rate was $18.2 \%$.

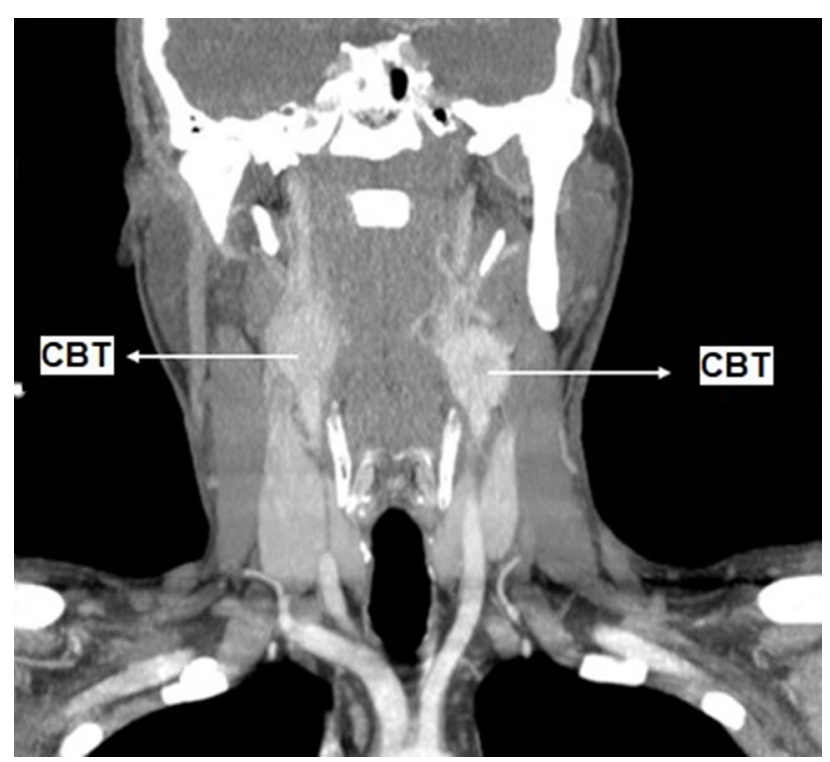

Figure 3. Computed tomography image showing bilateral carotid body tumors. 
Surgery is the definitive treatment method in the management of CBTs, but conservative approaches or radiotherapy can be also used in these patients. ${ }^{[13]}$ Despite the satisfactory results of the early grade of tumors, Shamblin type 3 tumors and tumors larger than $4 \mathrm{~cm}$ remain challenging cases for surgeons. Some attempts have been considered to facilitate surgery and reduce the associated complications. In the $1980 \mathrm{~s}$, considering the tumor receiving the blood supply from the ECA, devascularization of the ECA was suggested. ${ }^{[14,15]}$ Contrary to this assumption, in our experience, ligation of the ECA does not often reduce blood loss and does not facilitate dissection of the bifurcation.

Preoperative embolization before CBT surgery has become to be a current trend to reduces tumor size, surgical bleeding, and resection related complications. ${ }^{[16]}$ However, the effectiveness of embolization is still controversial. ${ }^{[17]}$ With the advances in endovascular surgery and prevalent use of coated stents, the collaterals of the tumor fed from the ECA have been bypassed, leaving the tumor to shrink or even disappear. These limited case reports suggest that without the use of intra-arterial gel foams, the risk of peri-procedural stroke may be reduced. ${ }^{[14]}$ However, these techniques are rarely used. In our study, we did not use any of the aforementioned techniques.

Although external radiotherapy is still a controversial treatment option, it can be used in patients in whom CBTs cannot be surgically removed. ${ }^{[18,19]}$ It has been demonstrated that radiotherapy slows down or temporarily stops tumor growth, but it is not a curative approach. ${ }^{[19]}$ In addition, in inoperable elderly patients and patients with multisystemic disease, considering the slow growth rates of their CBTs, watchful waiting or external radiotherapy may be a more appropriate treatment method. ${ }^{[20,21]}$ The long-term results of this treatment have not been shown, yet. Although radiotherapy is an appropriate approach for elderly patients, it is not a sufficient treatment for the young age group. ${ }^{[22,23]}$ In our seven patients, radiotherapy was used due to inadequate resection or disease recurrence.

In the treatment of Shamblin type 1 and 2 CBTs, removal of the tumor with careful subadventitial dissection is preferred. In type 3 tumors, reconstruction of the ECA or ICA may be required.
If massive bleeding occurs in type 3 tumors, the mass can be removed by clamping the arteries and, in the event of further damage occurring during the procedure, vascular reconstruction may be indicated. While eight of our patients required reconstruction, in three cases, ECA was ligated due to bleeding. Surgical removal of the tumor should be definitely preferred in patients with Shamblin type 3 tumors, and in patients under 50 years of age with long life expectancy. ${ }^{[4,24]}$

This study has several limitations that are inherent due to the retrospective design. We were unable to perform preoperative embolization to any patient during our study period. In particularly, the high complication rates in Shamblin type 3 class patients may indicate the need for pre- or intraoperative devascularization strategies in this patient group. In addition, the low number of Shamblin type 3 patients in the study period may have caused the complication rates in this patient group to be overestimated.

In conclusion, we believe that Shamblin type 1 and type 2 tumors can be treated safely with surgery and, since type 3 tumors are associated with high cranial nerve damage and high complication rates, a special attention is required during surgery, and radiotherapy would be a treatment alternative in cases with recurrent tumors and metastases.

\section{Declaration of conflicting interests}

The author declared no conflicts of interest with respect to the authorship and/or publication of this article.

\section{Funding}

The author received no financial support for the research and/or authorship of this article.

\section{REFERENCES}

1. Luna-Ortiz K, Rascon-Ortiz M, Villavicencio-Valencia V, Granados-Garcia M, Herrera-Gomez A. Carotid body tumors: Review of a 20-year experience. Oral Oncol 2005;41:56-61.

2. Sajid MS, Hamilton G, Baker DM; Joint Vascular Research Group. A multicenter review of carotid body tumour management. Eur J Vasc Endovasc Surg 2007;34:127-30.

3. Sykes JM, Ossoff RH. Paragangliomas of the head and neck. Otolaryngol Clin North Am 1986;19:755-67.

4. Sanlı A, Oz K, Ayduran E, Aydın S, Altın G, Eken M. Carotid body tumors and our surgical approaches. Indian J Otolaryngol Head Neck Surg 2012;64:158-61. 
5. O'Neill S, O'Donnell M, Harkin D, Loughrey M, Lee B, Blair P. A 22-year Northern Irish experience of carotid body tumours. Ulster Med J 2011;80:133-40.

6. Düzlü M, Yllmaz M, Tutar H, Karamert R, Sahin M, Karaloglu F, et al. Our surgical experience on carotid body paragangliomas and literature review. Gazi Medical Journal 2017;28:120-4.

7. Shamblin WR, ReMine WH, Sheps SG, Harrison EG Jr. Carotid body tumor (chemodectoma). Clinicopathologic analysis of ninety cases. Am J Surg 1971;122:732-9.

8. Kunt A, Bulut F, Demir CY. Karotis cisim tümörleri. Turkish J Thorac Cardiovasc Surg 2003;11:198-200.

9. Wang SJ, Wang MB, Barauskas TM, Calcaterra TC. Surgical management of carotid body tumors. Otolaryngol Head Neck Surg 2000;123:202-6.

10. Pacheco-Ojeda L. Malignant carotid body tumors: Report of three cases. Ann Otol Rhinol Laryngol 2001;110:36-40.

11. Köhler HF, Carvalho AL, Mattos Granja NV, Nishinari K, Kowalski LP. Surgical treatment of paragangliomas of the carotid bifurcation: Results of 36 patients. Head Neck 2004;26:1058-63.

12. Plukker JT, Brongers EP, Vermey A, Krikke A, van den Dungen JJ. Outcome of surgical treatment for carotid body paraganglioma. Br J Surg 2001;88:1382-6.

13. Koskas F, Vignes S, Khalil I, Koskas I, Dziekiewicz M, Elmkies F, et al. Carotid chemodectomas: Long-term results of subadventitial resection with deliberate external carotid resection. Ann Vasc Surg 2009;23:67-75.

14. Persky MS, Setton A, Niimi Y, Hartman J, Frank D, Berenstein A. Combined endovascular and surgical treatment of head and neck paragangliomas--a team approach. Head Neck 2002;24:423-31.

15. Dixon JL, Atkins MD, Bohannon WT, Buckley CJ, Lairmore TC. Surgical management of carotid body tumors: A 15-year single institution experience employing an interdisciplinary approach. Proc (Bayl Univ Med Cent) 2016;29:16-20.

16. Texakalidis P, Charisis N, Giannopoulos S, Xenos D, Rangel-Castilla L, Tassiopoulos AK, et al. Role of preoperative embolization in carotid body tumor surgery: A systematic review and meta-analysis. World Neurosurg 2019;129:503-13.e2.

17. Abu-Ghanem S, Yehuda M, Carmel NN, Abergel A, Fliss DM. Impact of preoperative embolization on the outcomes of carotid body tumor surgery: A meta-analysis and review of the literature. Head Neck 2016;38 Suppl 1:E2386-94.

18. Elshaikh MA, Mahmoud-Ahmed AS, Kinney SE, Wood BG, Lee JH, Barnett GH, et al. Recurrent head-and-neck chemodectomas: A comparison of surgical and radiotherapeutic results. Int J Radiat Oncol Biol Phys 2002;52:953-6.

19. Makek M, Franklin DJ, Zhao JC, Fisch U. Neural infiltration of glomus temporale tumors. Am J Otol 1990;11:1-5.

20. Gerosa M, Visca A, Rizzo P, Foroni R, Nicolato A, Bricolo A. Glomus jugulare tumors: The option of gamma knife radiosurgery. Neurosurgery 2006;59:561-9.

21. Woods CI, Strasnick B, Jackson CG. Surgery for glomus tumors: The Otology Group experience. Laryngoscope 1993;103(11 Pt 2 Suppl 60):65-70.

22. Green JD Jr, Brackmann DE, Nguyen CD, Arriaga MA, Telischi FF, De la Cruz A. Surgical management of previously untreated glomus jugulare tumors. Laryngoscope 1994;104:917-21.

23. Jansen TTG, Marres HAM, Kaanders JHAM, Kunst HPM. A meta-analysis on the surgical management of paraganglioma of the carotid body per Shamblin class. Clin Otolaryngol 2018.

24. Göde S, Denli Yalvaç Ş, Talas Z, Kılıç Z, Bozkurt AK. Karotis cisim tümörlerinde cerrahi deneyimimiz. Damar Cer Derg 2018;27:28-33. 